\title{
Early and long-term outcomes in the elderly: Comparison between off-pump and on-pump techniques in 1191 patients undergoing coronary artery bypass grafting
}

Yan Li, MD, Zhe Zheng, MD, and Shengshou Hu, MD

Objective: The aim of the present study was to investigate the influence of off-pump coronary artery bypass grafting on early and long-term mortality and morbidity in a consecutive series of elderly patients (aged $>65$ years) compared with conventional coronary artery bypass grafting.

Methods: From January of 1999 to December of 2003, data were extracted for 1191 patients aged more than 65 years: a conventional coronary artery bypass grafting group $(n=744)$ and an off-pump coronary artery bypass grafting group $(n=447)$. Age-related early outcomes of interest were in-hospital mortality and postoperative morbidities. Long-term outcomes, including total mortality, repeated revascularization, Q-wave myocardial infarction, stroke, readmission, and the combination of death, Q-wave myocardial infarction, stroke, and repeated revascularization, were evaluated with Cox regression analysis.

Results: Univariate analysis for early outcomes showed significant benefits from offpump coronary artery bypass grafting. After adjustment for baseline characteristics, there was still a benefit of off-pump coronary artery bypass grafting. Kaplan-Meier survival analyses (propensity matched cases) showed that stroke, major adverse cardiac and cerebrovascular events, and readmission occurred more frequently in the offpump coronary artery bypass grafting group $(P<.001)$. There was a nonsignificant trend to higher total mortality $(P=.193)$ and higher repeated revascularization rates $(P=.067)$ in the off-pump coronary artery bypass grafting group. Cox regression for long-term outcomes showed that patients in the off-pump coronary artery bypass grafting group had a higher incidence of stroke (hazard ratio $2.611,95 \%$ confidence interval 2.152-3.070), readmission (hazard ratio 2.000, 95\% confidence interval 1.747-2.253), and major adverse cardiac and cerebrovascular events (hazard ratio $1.764,95 \%$ confidence interval $1.456-2.072$ ).

From the Department of Cardiovascular Surgery, Cardiovascular Institute and Fuwai Hospital, CAMS, Beijing, China.

Received for publication Sept 19, 2007; revisions received Nov 19, 2007; accepted for publication Dec 18, 2007.

Address for reprints: Shengshou Hu, MD, Department of Cardiovascular Surgery, Cardiovascular Institute and Fuwai Hospital, Chinese Academy of Medical Sciences, 167 Beilishilu, Beijing, China 100037 (E-mail: huss@vip.sohu.com).

J Thorac Cardiovasc Surg 2008;136:657-64 0022-5223/\$34.00

Copyright $\odot 2008$ by The American Association for Thoracic Surgery

doi:10.1016/j.jtcvs.2007.12.069
Conclusion: Our analysis shows that off-pump coronary artery bypass grafting compared with conventional coronary artery bypass grafting was associated with favorable early outcomes in the elderly population. However, the early benefits of off-pump coronary artery bypass grafting were not maintained in the long term, and off-pump coronary artery bypass grafting showed trends toward worse longterm results.

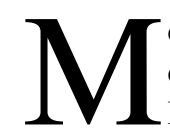
ost countries have accepted the chronologic age of 65 years as a definition of "elderly," and the expansion of the elderly population worldwide has led to a dramatic increase in the number of patients aged more than 65 years. Because of a higher incidence of coronary artery disease in the developing world, surgical revascularization in the elderly is increasing. Although coronary revascularization in these patients is associated with an increased risk of mortality and postoperative morbidities, the improvements in surgical, anesthetic, and perfusion 


\section{Abbreviations and Acronyms \\ $\mathrm{CABG}=$ coronary artery bypass grafting \\ $\mathrm{CCABG}=$ conventional coronary artery bypass grafting \\ $\mathrm{CPB}=$ cardiopulmonary bypass \\ OPCAB $=$ off-pump coronary artery bypass \\ $\mathrm{MACCE}=$ major adverse cardiac and cerebrovascular event \\ PVD = peripheral vascular disease}

rotids. Cerebrovascular disease was defined by a history of any one of the following: unresponsive coma more than 24 hours, cerebrovascular accident (symptoms $>72$ hours after onset), reversible ischemic neurologic deficit (recovery within 72 hours), and transient ischemic attack (recovery within 24 hours). Previous stroke was defined as a history of central neurologic deficit persisting more than 72 hours. Hyperlipidemia was defined as a history of hyperlipidemia diagnosed or treated by a physician. Renal failure was defined as a documented history of renal failure or a history of a serum creatinine greater than $200 \mu \mathrm{mol} / \mathrm{L}$. Unstable angina was defined as rest angina requiring intravenous nitrates until arrival in the operating room. Critical preoperative state was defined by any one or more of the following: ventricular tachycardia or fibrillation or rescued sudden death, preoperative cardiac massage, preoperative ventilation before arrival in the operating room, preoperative inotropic support, and intraaortic balloon pump or preoperative acute renal failure (anuria or oliguria $<10 \mathrm{~mL} / \mathrm{h}$ ). Incomplete revascularization was identified by comparing the number of distal anastomoses with the number of diseased vessels observed on the preoperative coronary angiogram. During the early postoperative period, postoperative low cardiac output syndrome was defined as a cardiac index less than $2.0 \mathrm{~L} / \mathrm{min} / \mathrm{m}^{2}$ and the postoperative need for left ventricular assist device, intraaortic balloon pump, and inotrope support. Stroke was defined as new acute focal neurologic deficit with signs and symptoms lasting greater than 24 hours, and neurologic events included transient ischemic attack and stroke. New renal failure was defined as prolonged oliguria or anuria requiring dialysis or hemofiltration. Pulmonary complication included prolonged mechanical ventilation ( $>24$ hours), reintubation, and pneumonia, which was diagnosed by sputum culture and radiographic findings. Infective complications included sepsis, deep sternal infection, mediastinitis, and leg wounds infection as defined by positive culture and requiring antibiotic therapy. During the follow-up period, total mortality was defined as all causes of mortality. Q-wave myocardial infarction was defined as new significant Q waves in continuous leads documented in medical record. Repeated revascularization was defined as new $\mathrm{CABG}$ procedure or percutaneous coronary intervention with documented graft failure or new culprit lesion. Stroke was defined as new acute focal neurologic deficit with signs and symptoms lasting greater than 24 hours documented in a medical record. Major adverse cardiac and cerebrovascular events (MACCEs) were the combination of death, Q-wave myocardial infarction, stroke, and repeated revascularization. Readmission was defined as any cardiovascular hospital readmissions for acute myocardial infarction, congestive heart failure, and unstable angina.

\section{Statistical Analysis}

Age-related early outcomes of interest were in-hospital mortality and postoperative morbidities. Long-term outcomes of interest were total mortality, repeated revascularization, stroke, Q-wave myocardial infarction, readmission, and MACCEs during the entire follow-up. Continuous variables were presented as mean \pm standard deviation. Comparisons between means were performed using the Student $t$ test, whereas differences in categoric variables were assessed using the Fisher's exact test or chi-square test. Early outcomes were compared with or without risk adjusting, using logistic regression.

A propensity-matched analysis was used to adjust for selection bias between OPCAB versus CCABG. The propensity score was 
calculated for each patient on the basis of a logistic regression analysis of the predicted probability of OPCAB. All of the preoperative patient risk factors available were used as candidate variables in this propensity model. The significant predictors of surgery type were used to match each patient in the OPCAB group to a patient in the CCABG group with the same set of predictors. A total of 610 of 1191 patients were matched. Survival curves of the propensity score matched cases were generated using the Kaplan-Meier method, and group differences were assessed by the log-rank test.

Multivariable stepwise Cox proportional hazards models were created with the use of preoperative, intraoperative, and postoperative variables to identify independent predictors of total mortality and other long-term outcomes. The candidate variables include age, gender, chronic obstructive pulmonary disease, PVD, cerebrovascular disease, history of stroke, hypertension, hyperlipidemia, diabetes, previous cardiac operation, renal failure, serum creatinine, unstable angina, depressed left ventricular ejection fraction $(<50 \%)$, recent myocardial infarction, critical operative state, emergency operation, EuroSCORE, left main disease, triple-vessel disease, off-pump technique, absence of internal thoracic artery graft, incomplete revascularization, postoperative neurologic event, low cardiac output syndrome, new-onset atrial fibrillation, new renal failure, pulmonary complication, infective complication, and gastrointestinal compilation. Only variables with a $P$ value less than .05 at univariate analysis were included in the regression model. All statistical tests were 2 tailed. Statistical analyses were performed using SPSS version 13.0 (SPSS Inc, Chicago, Ill).

\section{Results}

\section{Patients}

A total of 1191 patients aged 65 years or more underwent coronary artery bypass surgery. Of these patients, $744(62.5 \%)$ were in the CCABG group and 447 (37.5\%) were in the OP$\mathrm{CAB}$ group. Baseline preoperative and intraoperative characteristics are listed in Table 1. Patients in OPCAB group were significantly older $(70.0 \pm 3.9$ years vs $69.1 \pm 3.4$ years, $P<$ $.001)$, had a higher incidence of PVD $(15.4 \%$ vs $6.6 \%, P<$ $.001)$, had a higher EuroSCORE (4.01 \pm 1.68 vs $3.59 \pm$ $1.51, P<.001)$, had a higher rate of use of internal thoracic artery graft $(94.9 \%$ vs $91.7 \%, P=.039)$, had a higher rate of incomplete revascularization $(16.3 \%$ vs $3.2 \%, P<.001)$, and had more arterial distal anastomoses $(1.00 \pm 0.35$ vs $0.94 \pm$ $0.37, P=.006)$. However, patients in the CCABG group had a higher prevalence of triple vessel disease $(88.4 \%$ vs $83.9, P$ $<.001)$, a higher ratio of grafts/diseased vessels (1.342 \pm 0.32 vs $1.10 \pm 0.31, P<.001)$, and more venous distal anastomoses $(2.89 \pm 0.96$ vs $2.03 \pm 0.92, P<.001)$.

\section{Early Outcome}

The in-hospital mortality rate for overall patients in our study was low ( $\mathrm{n}=26,2.18 \%$ ). The early clinical outcome and risk-adjusted analysis are shown in Table 2. Univariate analysis showed significant benefits from OPCAB for pulmonary complications $(14.5 \%$ vs $6.3 \%, P<.001)$, infective complications $(3.8 \%$ vs $1.1 \%, P=.007)$, and length of intensive
TABLE 1. Baseline preoperative and intraoperative characteristics

\begin{tabular}{|c|c|c|c|}
\hline & CCABG $(n=744)$ & OPCAB $(n=447)$ & \\
\hline & n (\%) & n (\%) & $P$ value \\
\hline Age & $69.10 \pm 3.38$ & $70.04 \pm 3.94$ & $<.001$ \\
\hline Female & $140(18.8)$ & 77 (17.2) & NS \\
\hline COPD & $184(24.7)$ & $117(26.2)$ & NS \\
\hline PVD & $49(6.6)$ & $69(15.4)$ & $<.001$ \\
\hline CVD & $70(9.4)$ & $59(13.2)$ & NS \\
\hline Previous stroke & $63(8.5)$ & $43(9.6)$ & NS \\
\hline Hypertension & $464(62.4)$ & $289(64.7)$ & NS \\
\hline Hyperlipidemia & $240(32.3)$ & $145(32.4)$ & NS \\
\hline Diabetes & $225(30.2)$ & $130(29.1)$ & NS \\
\hline $\begin{array}{l}\text { Prior cardiac } \\
\text { operation }\end{array}$ & $1(0.1)$ & $3(0.7)$ & NS \\
\hline Renal failure & $8(1.1)$ & $10(2.2)$ & NS \\
\hline Serum creatinine & $93.70 \pm 20.91$ & $94.09 \pm 21.71$ & NS \\
\hline Unstable angina & $60(8.1)$ & $39(8.7)$ & NS \\
\hline \multicolumn{4}{|l|}{ LVEF } \\
\hline LVEF $<30 \%$ & $5(0.7)$ & $2(0.4)$ & NS \\
\hline LVEF $30 \%-50 \%$ & $159(21.4)$ & $75(16.8)$ & NS \\
\hline Recent $\mathrm{Ml}<21 \mathrm{~d}$ & $13(1.7)$ & $12(2.7)$ & NS \\
\hline $\begin{array}{l}\text { Critical preoperative } \\
\text { state }\end{array}$ & $7(0.9)$ & $9(2.0)$ & NS \\
\hline Left main disease & $275(37.0)$ & $140(31.3)$ & NS \\
\hline Triple-vessel disease & $658(88.4)$ & 375 (83.9) & $<.001$ \\
\hline Emergency operation & $44(5.9)$ & $28(6.3)$ & NS \\
\hline EuroSCORE & $3.59 \pm 1.51$ & $4.01 \pm 1.68$ & $<.001$ \\
\hline $\begin{array}{l}\text { No. of arterial } \\
\text { distal anastomoses }\end{array}$ & $0.94 \pm 0.37$ & $1.00 \pm 0.35$ & .006 \\
\hline $\begin{array}{l}\text { No. of venous } \\
\text { distal anastomoses }\end{array}$ & $2.89 \pm 0.96$ & $2.03 \pm 0.92$ & $<.001$ \\
\hline ITA graft & $682(91.7)$ & $424(94.9)$ & .039 \\
\hline $\begin{array}{l}\text { Incomplete } \\
\text { revascularization }\end{array}$ & $24(3.2)$ & 73 (16.3) & $<.001$ \\
\hline $\begin{array}{l}\text { Grafts/diseased } \\
\text { vessel }\end{array}$ & $1.34 \pm 0.32$ & $1.10 \pm 0.31$ & $<.001$ \\
\hline
\end{tabular}

$C O P D$, Chronic obstructive pulmonary disease; $P V D$, peripheral vascular disease; $C V D$, cerebrovascular disease; $L V E F$, left ventricular ejection fraction; $M I$, myocardial infarction; ITA, internal thoracic artery. Continuous variables are reported as mean \pm standard deviation.

care unit stay $(99.6 \pm 124.7$ vs $83.1 \pm 138.9, P=.004)$. It also showed a benefit of OPCAB for stroke, new renal failure, intraaortic balloon pump use, inotrope use, and low cardiac output syndrome. After adjustment for age, gender, PVD, EuroSCORE, triple vessel disease, and grafts/diseased vessels, there was still a benefit of OPCAB. Table 2 shows that the adjusted odds ratios favoring the OPCAB group were 2.627 for pulmonary complication, 1.575 for low cardiac output syndrome, 2.334 for reoperation, and 3.354 for infection-related complication. Table 2 also shows that there were no significant differences in in-hospital mortality and postoperative hospital stay between the 2 groups. 
TABLE 2. Early clinical outcomes ${ }^{\mathrm{a}}$

\begin{tabular}{|c|c|c|c|c|c|c|}
\hline & $\frac{\text { CCABG }(n=744)}{n(\%)}$ & $\frac{\text { OPCAB }(n=447)}{n(\%)}$ & $P$ value & $\mathbf{O} \mathbf{R}^{\mathrm{b}}$ (adjusted) & $95 \% \mathrm{CI}$ & $P$ value \\
\hline In-hospital mortality & $20(2.7)$ & $6(1.3)$ & NS & 2.352 & $0.848-6.527$ & NS \\
\hline Postoperative hospital stay (d) & $15.30 \pm 79.72$ & $10.99 \pm 29.39$ & NS & & & \\
\hline ICU stay (h) & $99.64 \pm 124.68$ & $83.10 \pm 138.85$ & .004 & & & \\
\hline Postoperative morbidities & $298(40.1)$ & $150(33.6)$ & .025 & 1.329 & $1.007-1.755$ & .045 \\
\hline Neurologic event & $24(3.2)$ & $6(1.3)$ & .045 & 2.386 & $0.862-6.605$ & NS \\
\hline Stroke & $8(1.1)$ & $0(0.0)$ & .028 & & & \\
\hline Low cardiac output syndrome & $190(25.5)$ & $90(20.1)$ & .033 & 1.575 & $1.138-2.180$ & .006 \\
\hline IABP support & $23(3.1)$ & $4(0.9)$ & .015 & 3.995 & $1.224-13.036$ & .022 \\
\hline LVAD support & $5(0.7)$ & $0(0.0)$ & NS & & & \\
\hline Significant inotrope support & $125(16.8)$ & $51(11.4)$ & .011 & 1.811 & $1.217-2.695$ & .003 \\
\hline New-onset atrial fibrillation & $111(14.9)$ & $73(16.3)$ & NS & 0.868 & $0.602-1.252$ & NS \\
\hline New renal failure & $9(1.2)$ & $0(0.0)$ & .017 & & & \\
\hline Dialysis & $2(0.3)$ & $0(0.0)$ & NS & & & \\
\hline Pulmonary complications & $108(14.5)$ & $28(6.3)$ & .000 & 2.627 & $1.607-4.295$ & .000 \\
\hline Infective complications & $28(3.8)$ & $5(1.1)$ & .007 & 3.354 & $1.189-9.466$ & .022 \\
\hline Gastrointestinal complication & $9(1.2)$ & $6(1.3)$ & NS & 1.060 & $0.340-3.309$ & NS \\
\hline Reexploration for bleeding & $17(2.3)$ & $7(1.6)$ & NS & 1.233 & $0.451-3.371$ & NS \\
\hline Reexploration for graft occlusion & $3(0.4)$ & $0(0.0)$ & NS & & & \\
\hline
\end{tabular}

$O R$, odds ratio; $C l$, confidence interval; $I C U$, intensive care unit; $I A B P$, intraaortic balloon pump; $L V A D$, left ventricular assist device; $N S$, not significant. ${ }^{2} V a r i-$ ables are reported as frequencies $(\%)$ or means \pm standard deviation. ${ }^{b} 0 \mathrm{dds}$ ratio adjusted by variables significantly related to CCABG and $O P C A B$ in Table 1 .

\section{Long-term Outcome}

Figure 1 shows the Kaplan-Meier event-free survival analyses (propensity score matched cases) for long-term outcomes. The log-rank test was used to describe the differences between OPCAB and CCABG surgery using the matched data. Stroke, MACCEs, and readmission occurred more frequently in the OPCAB group $(P<.001)$. There was a nonsignificant trend to higher total mortality $(P=.193)$ and higher repeated revascularization rates $(P=.067)$ in the OPCAB group. There were no significant differences in Q-wave myocardial infarction $(P=.817)$.

Table 3 summarizes the results of univariate and multivariate analyses (Cox regression model) in identifying the preoperative, intraoperative, and postoperative risk factors associated with the long-term outcomes. The candidate independent variables used in stepwise Cox proportional hazards models are listed in Table 3. Intraoperatively, the off-pump technique was shown to be a significant predictor of stroke (hazard ratio $=2.611 ; P<.001$ ), readmission (hazard ratio $=2.000 ; P<.001$ ), and MACCEs (hazard ratio $=1.764$; $P<.001)$.

\section{Discussion}

The analysis carried out in the present study focused on the influence of the off-pump surgical technique on early and long-term clinical outcome in the elderly population. The most important result of our study is that despite more favorable early outcomes, the benefits of OPCAB cannot be maintained in the long term.
CCABG is performed with the help of cardiopulmonary bypass, which allows the surgeon to perform the delicate anastomoses on an arrested heart under optimal visualization. However, previous studies have demonstrated that the use of CPB during CABG is associated with substantial complications, ${ }^{6-11}$ which are largely attributed to the CPB itself and the aortic cannulation and crossclamping. OPCAB does not require hypothermia, $\mathrm{CPB}$, aortic cannulation, or crossclamping. In reviewing meta-analyses comparing early outcomes after OPCAB and CCABG, we found that it has been accepted that OPCAB is associated with a lower incidence of postoperative morbidities in the short term. ${ }^{12-16} \mathrm{Ta}-$ ble 2 shows that the early outcome in our study also favored the OPCAB group. These findings are in accordance with the aforementioned meta-analyses suggesting that OPCAB may reduce in-hospital morbidity in elderly surgical patients.

However, the exposure of the vessels at the back of the heart (circumflex artery) is sometimes difficult during OP$\mathrm{CAB}$, and the motion of the heart may impede the anastomotic process. Many trials have reported fewer grafts being performed with OPCAB so that the degree of revascularization is less. Khan and colleagues ${ }^{17}$ reported a significant reduction in the patency rate associated with OPCAB compared with CCABG, ${ }^{17}$ and a registry from New York State demonstrated a lower survival and freedom from revascularization with OPCAB compared with $\mathrm{CCABG} .{ }^{18} \mathrm{In}$ our study, patients in the OPCAB group had more internal thoracic artery grafts and arterial distal anastomoses but a lower ratio of grafts/diseased vessels and a higher rate of 

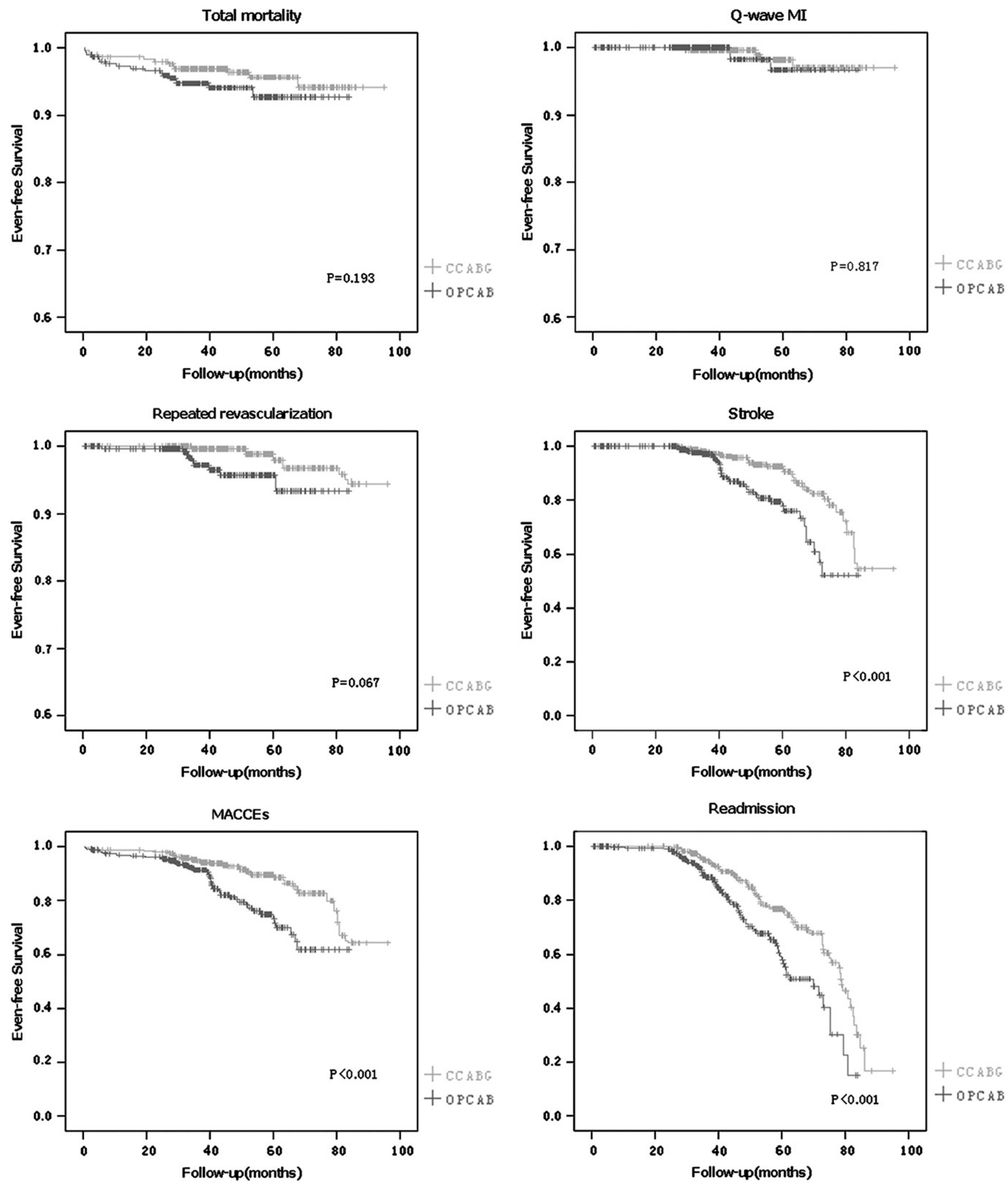

Figure 1. Kaplan-Meier curves for event-free survival analyses in total mortality, 0-wave myocardial infarction, repeated revascularization, stroke, MACCEs, and readmission (propensity score matched cases). CCABG, Conventional coronary artery bypass grafting; $O P C A B$, off-pump coronary artery bypass; $M A C C E$, major adverse cardiac and cerebrovascular event. 
TABLE 3. Preoperative, intraoperative, and postoperative risk factors of long-term outcomes for operative survivors according to univariate and multivariate analysis*

\begin{tabular}{|c|c|c|c|c|c|c|c|c|}
\hline & \multicolumn{4}{|c|}{ Total Mortality } & \multicolumn{4}{|c|}{ Repeated revascularization } \\
\hline & \multirow{2}{*}{$\frac{\text { Univariate Analysis }}{p}$} & \multicolumn{3}{|c|}{ Multivariate Analysis } & \multirow{2}{*}{$\begin{array}{c}\text { Univariate Analysis } \\
p \\
\end{array}$} & \multicolumn{3}{|c|}{ Multivariate Analysis } \\
\hline & & $\boldsymbol{p}$ & $H R$ & $95 \% \mathrm{Cl}$ & & $p$ & $H R$ & $95 \% \mathrm{Cl}$ \\
\hline \multicolumn{9}{|l|}{ Preopearative } \\
\hline Age & n.s. & & & & 0.035 & 0.010 & 1.110 & $1.026-1.201$ \\
\hline Female & n.s. & & & & 0.025 & 0.005 & 2.882 & $1.368-6.074$ \\
\hline COPD & n.s. & & & & n.s. & & & \\
\hline PVD & n.s. & & & & n.s. & & & \\
\hline CVD & n.s. & & & & 0.009 & 0.004 & 3.209 & $1.459-7.060$ \\
\hline Stroke & n.s. & & & & n.s. & & & \\
\hline Hypertension & n.s. & & & & n.s. & & & \\
\hline Hyperlipidemia & n.s. & & & & n.s. & & & \\
\hline Diabetes & n.s. & & & & n.s. & & & \\
\hline Prior cardiac opeartion & n.s. & & & & 0.011 & 0.002 & 23.806 & $3.122-181.504$ \\
\hline Renal failure & 0.026 & & & & 0.021 & 0.012 & 6.375 & $1.507-26.966$ \\
\hline Serum creatinine & 0.003 & 0.028 & 1.011 & $1.001-1.022$ & n.s. & & & \\
\hline Unstable angina & n.s. & & & & n.s. & & & \\
\hline LVEF $<50 \%$ & 0.001 & 0.006 & 2.083 & $1.554-2.612$ & n.s. & & & \\
\hline Recent $\mathrm{MI}<21$ days & n.s. & & & & n.s. & & & \\
\hline Critical preoperative state & n.s. & & & & n.s. & & & \\
\hline Left main disease & n.s. & & & & n.s. & & & \\
\hline Triple-vessel disease & n.s. & & & & n.s. & & & \\
\hline Emergency operation & n.s. & & & & n.s. & & & \\
\hline EuroSCORE & n.s. & & & & 0.012 & & & \\
\hline \multicolumn{9}{|l|}{ Intraoperative } \\
\hline Off-pump & n.s. & & & & n.s. & & & \\
\hline Absence of IMA graft & n.s. & & & & n.s. & & & \\
\hline Incomplete revascularization & n.s. & & & & n.s. & & & \\
\hline \multicolumn{9}{|l|}{ Postoperative } \\
\hline Neurological event & n.s. & & & & n.s. & & & \\
\hline Low cardiac output syndrome & $<0.001$ & 0.001 & 2.403 & $1.444-3.999$ & n.s. & & & \\
\hline New onset AF & 0.005 & & & & n.s. & & & \\
\hline New renal failure & 0.052 & & & & n.s. & & & \\
\hline Pulmonary complictions & 0.003 & & & & n.s. & & & \\
\hline Infective complications & n.s. & & & & n.s. & & & \\
\hline Gastrointestinal complications & 0.001 & 0.003 & 6.200 & $1.885-20.396$ & n.s. & & & \\
\hline
\end{tabular}

*Abbreviations are as shown in Tables1 and 2.

incomplete revascularization, all of which are related to prognosis.

With respect to long-term outcomes, we found a nonsignificant trend to higher rates of total mortality and repeated revascularization. Less information is available from other studies on comparative long-term outcomes after CABG, but evidence exists of higher rates of long-term mortality and repeated revascularization. Racz and colleagues ${ }^{18}$ found that patients undergoing OPCAB had higher rates of mortality and subsequent revascularization. Wijeysundera and colleagues ${ }^{19}$ also found higher long-term (1 to 2 years) repeated revascularization in a meta-analysis of randomized and observational studies.
Stroke is a serious complication after coronary surgery and influences the long-term prognosis of elderly patients. Previous studies have shown that advanced age, hypertension, PVD, previous stroke, diabetes mellitus, depressed left ventricular ejection fraction, and chronic renal failure are all identified as independent determinants for stroke after cardiac surgery. ${ }^{20,21}$ Our study patients in the OPCAB group were significantly older and had a higher incidence of PVD. With multivariable Cox regression, the off-pump technique was shown to be a significant predictor of stroke. We also attempted propensity score matching to balance all the preoperative variables available. In these propensity score-matched cases, stroke still occurred more frequently in the OPCAB group. 
TABLE 3. (Continued)

\begin{tabular}{|c|c|c|c|c|c|c|c|c|c|c|c|}
\hline \multicolumn{4}{|c|}{ Stroke } & \multicolumn{4}{|c|}{ Readmission } & \multicolumn{4}{|c|}{ MACCES } \\
\hline \multirow{2}{*}{$\frac{\text { Univariate Analysis }}{p}$} & \multicolumn{3}{|c|}{ Multivariate Analysis } & \multirow{2}{*}{$\frac{\text { Univariate Analysis }}{p}$} & \multicolumn{3}{|c|}{ Multivariate Analysis } & \multirow{2}{*}{$\frac{\text { Univariate Analysis }}{p}$} & \multicolumn{3}{|c|}{ Multivariate Analysis } \\
\hline & $\boldsymbol{p}$ & $H R$ & $95 \% \mathrm{Cl}$ & & $p$ & $H R$ & $95 \% \mathrm{Cl}$ & & $p$ & $H R$ & $95 \% \mathrm{Cl}$ \\
\hline$<0.001$ & 0.001 & 1.093 & $1.037-1.153$ & $<0.001$ & 0.017 & 1.042 & $1.007-1.078$ & $<0.001$ & & & \\
\hline n.s. & & & & $<0.001$ & 0.001 & 1.644 & $1.222-2.211$ & n.s. & & & \\
\hline n.s. & & & & n.s. & & & & n.s. & & & \\
\hline 0.018 & & & & $<0.001$ & 0.006 & 1.787 & $1.181-2.703$ & n.s. & & & \\
\hline 0.008 & 0.006 & 2.237 & $1.254-3.992$ & 0.004 & 0.017 & 1.527 & $1.078-2.163$ & 0.002 & 0.004 & 1.799 & $1.206-2.684$ \\
\hline 0.020 & & & & 0.034 & & & & 0.005 & & & \\
\hline n.s. & & & & 0.013 & & & & n.s. & & & \\
\hline n.s. & & & & n.s. & & & & n.s. & & & \\
\hline n.s. & & & & n.s. & & & & n.s. & & & \\
\hline n.s. & & & & n.s. & & & & n.s. & & & \\
\hline n.s. & & & & n.s. & & & & 0.011 & 0.041 & 2.347 & $1.034-5.330$ \\
\hline n.s. & & & & n.s. & & & & n.s. & & & \\
\hline 0.040 & & & & $<0.001$ & & & & 0.035 & & & \\
\hline 0.033 & & & & n.s. & & & & n.s. & & & \\
\hline n.s. & & & & n.s. & & & & n.s. & & & \\
\hline n.s. & & & & n.s. & & & & n.s. & & & \\
\hline n.s. & & & & n.s. & & & & n.s. & & & \\
\hline n.s. & & & & n.s. & & & & n.s. & & & \\
\hline 0.011 & 0.019 & 2.573 & $1.165-5.681$ & 0.006 & & & & n.s. & & & \\
\hline$<0.001$ & & & & $<0.001$ & 0.000 & 1.172 & $1.0730-1.280$ & $<0.001$ & 0.001 & 1.166 & $1.066-1.276$ \\
\hline$<0.001$ & 0.000 & 2.611 & $2.152-3.070$ & $<0.001$ & 0.000 & 2.000 & $1.747-2.253$ & $<0.001$ & 0.000 & 1.764 & $1.456-2.072$ \\
\hline n.s. & & & & n.s. & & & & n.s. & & & \\
\hline n.s. & & & & 0.005 & & & & 0.035 & & & \\
\hline n.s. & & & & n.s. & & & & n.s. & & & \\
\hline n.s. & & & & 0.028 & & & & 0.004 & 0.140 & 1.539 & $1.090-2.174$ \\
\hline n.s. & & & & n.s. & & & & 0.029 & & & \\
\hline n.s. & & & & n.s. & & & & n.s. & & & \\
\hline n.s. & & & & 0.025 & 0.034 & 1.498 & $1.031-2.176$ & 0.027 & & & \\
\hline n.s. & & & & n.s. & & & & n.s. & & & \\
\hline n.s. & & & & n.s. & & & & 0.026 & 0.051 & 2.711 & $0.994-7.393$ \\
\hline
\end{tabular}

Readmission in our present study was defined as any cardiovascular hospital readmissions for acute myocardial infarction, congestive heart failure, and unstable angina. Patients in the OPCAB group were more likely than patients in the CCABG group to be readmitted during follow-up. With multivariable Cox regression, the off-pump technique was also shown to be a significant predictor of readmission. MACCEs were the combination of death, Q-wave myocardial infarction, stroke, and repeated revascularization; therefore, MACCEs occurred more frequently in the OPCAB group.

Patients in the OPCAB group were significantly older and had a higher EuroSCORE, higher prevalence of PVD, and higher rate of incomplete revascularization, which may explain their worse long-term results. However, we were unable to determine the extent to which the higher rates of these long-term adverse outcomes in the OPCAB group were related to choice of procedure or incomplete revascularization versus other risk factors. We believe this will be important because choice of procedure or incomplete revascularization may be easily remedied by changing practice pattern. A large, randomized clinical trial is warranted to confirm the influence of the offpump technique on the long-term outcomes in elderly patients.

\section{Potential Clinical Implications of Data}

Because OPCAB showed trends toward early benefit but worse long-term result, it is possible that a larger sample 
size and longer-term follow-up might revealed other statistically significant outcome variables. A randomized trial is indicated because randomization, as with all trials comparing OPCAB with CCABG, eliminates clinical judgment in patient selection and carries a potential for being misleading as a predictor of outcomes in actual daily life.

\section{Study Limitations}

The nonrandomized nature of the study limits any direct comparisons of the 2 surgical procedures of coronary revascularization. We included all patients aged more than 65 years undergoing isolated $\mathrm{CABG}$, resulting in a heterogeneous population of elderly patients with some baseline clinical differences between the study groups. This study was observational, uncontrolled, and without specific protocols, therefore limiting any direct comparisons of the 2 procedures. Perioperative myocardial infarction was not evaluated in our study because cardiac enzymes were not routinely obtained after revascularization. Patients were subject to treatment bias because the decision to proceed with OPCAB versus CCABG was made solely at the discretion of the operating surgeon on the basis of anatomic and clinical findings. We attempted to minimize this bias by matching patients exactly on the basis of patient-related factors in our database that were significant predictors of the type of procedure in multivariable analyses. However, the selection bias may still be present because of some undefined factors related to the choice of procedure and adverse outcomes that were not present in our database, for example, an extensively calcified ascending aorta, the target vessel size, and the extent of disease in the target vessel.

\section{Conclusions}

OPCAB compared with CCABG reduced early morbidities in elderly patients. However, the early benefits of OPCAB could not be maintained in the long term, and OPCAB showed trends toward worse long-term results. A large, randomized clinical trial is warranted to confirm the influence of the off-pump technique in elderly patients.

\section{References}

1. Ascione R, Caputo M, Angelini GD. Off-pump coronary artery bypass grafting: not a flash in the pan. Ann Thorac Surg. 2003;75:306-13.

2. Athanasiou T, Al-Ruzzeh S, Kumar P, et al. Off-pump myocardial revascularization is associated with less incidence of stroke in elderly patients. Ann Thorac Surg. 2004;77:745-53.

3. Athanasiou T, Aziz O, Mangoush O, et al. Does off-pump coronary artery bypass reduce the incidence of post-operative atrial fibrillation? A question revisited. Eur J Cardiothorac Surg. 2004;26:701-10.

4. Lin CY, Hong GJ, Lee KC, et al. Off-pump technique in coronary artery bypass grafting in elderly patients. Aust N Z J Surg. 2003;73:473-6.
5. Deuse T, Detter C, Samuel V, et al. Early and midterm results after coronary artery bypass grafting with and without cardiopulmonary bypass: which patient population benefits the most? Heart Surg Forum. 2003;6: $77-83$.

6. Mack MJ, Brown PP, Kugelmass AD, et al. Current status and outcomes of coronary revascularization 1999 to 2002: 148,396 surgical and percutaneous procedures. Ann Thorac Surg. 2004;77:761-6.

7. Stamou SC, Hill PC, Dangas G, et al. Stroke after coronary artery bypass: incidence, predictors, and clinical outcome. Stroke. 2001;32: 1508-13.

8. Stover EP, Siegel LC, Parks R, et al. Variability in transfusion practice for coronary artery bypass surgery persists despite national consensus guidelines: a 24-institution study. Institutions of the Multicenter Study of Perioperative Ischemia Research Group. Anesthesiology. 1998;88: 327-33.

9. Mathew JP, Parks R, Savino JS, Friedman AS, Koch C, Mangano DT, Browner WS. Atrial fibrillation following coronary artery bypass graft surgery: predictors, outcomes, and resource utilization. MultiCenter Study of Perioperative Ischemia Research Group. JAMA. 1996;276: 300-6.

10. Mathew JP, Fontes ML, Tudor IC, et al. Investigators of the Ischemia Research and Education Foundation; Multicenter Study of Perioperative Ischemia Research Group. A multicenter risk index for atrial fibrillation after cardiac surgery. JAMA. 2004;291:1720-9.

11. Sellke FW, DiMaio JM, Caplan LR, et al. American Heart Association. Comparing on-pump and off-pump coronary artery bypass grafting: numerous studies but few conclusions: a scientific statement from the American Heart Association council on cardiovascular surgery and anesthesia in collaboration with the interdisciplinary working group on quality of care and outcomes research. Circulation. 2005;111: 2858-64.

12. Panesar SS, Athanasiou T, Nair S, et al. Early outcomes in the elderly: a meta-analysis of 4921 patients undergoing coronary artery bypass grafting-comparison between off-pump and on-pump techniques. Heart. 2006;92:1808-16.

13. Reston JT, Tregear SJ, Turkelson CM. Meta-analysis of short-term and mid-term outcomes following off-pump coronary artery bypass grafting. Ann Thorac Surg. 2003;76:1510-5.

14. Cheng DC, Bainbridge D, Martin JE, et al. Evidence-Based Perioperative Clinical Outcomes Research Group. Does off-pump coronary artery bypass reduce mortality, morbidity, and resource utilization when compared with conventional coronary artery bypass? A meta-analysis of randomized trials. Anesthesiology. 2005;102:188-203.

15. Van der Heijden GJ, Nathoe HM, Jansen EW, et al. Meta-analysis on the effect of off-pump coronary bypass surgery. Eur J Cardiothorac Surg. 2004;26:81-4.

16. Parolari A, Alamanni F, Cannata A, et al. Off-pump versus on-pump coronary artery bypass: meta-analysis of currently available randomized trials. Ann Thorac Surg. 2003;76:37-40.

17. Khan NE, De Souza A, Mister R, et al. A randomized comparison of offpump and on-pump multivessel coronary-artery bypass surgery. $N$ Engl J Med. 2004;350:21-8.

18. Racz MJ, Hannan EL, Isom OW, et al. A comparison of short- and long-term outcomes after off-pump and on-pump coronary artery bypass graft surgery with sternotomy. J Am Coll Cardiol. 2004;43: $557-64$.

19. Wijeysundera DN, Beattie WS, Djaiani G, et al. Off-pump coronary artery surgery for reducing mortality and morbidity: meta-analysis of randomized and observational studies. J Am Coll Cardiol. 2005;46: 872-82.

20. Hogue CW, Murphy SF, Schechtman KB, Davila-Roman VG. Risk factors for early or delayed stroke after cardiac surgery. Circulation. 1999; 100:642-7.

21. Stamou SC, Hill PC, Dangas G, et al. Stroke after coronary artery bypass. Incidence, predictors, and clinical outcome. Stroke. 2001;32: 1508-13. 